\title{
AS DOENÇAS E OS DOENTES - A APREENSÃO DAS PRÁTICAS MÉDICAS NO MODO DE PRODUÇÃO CAPITALISTA
}

Cleuza P. Ornellas*

ORNELLAS, C.P. As doenças e os doentes - a apreensão das práticas médicas no modo de produção capitalista.

Rev.latino-am.enfermagem, Ribeirão Preto, v. 7, n. 1, p. 19-26, janeiro 1999.

Este artigo discute as doenças e os doentes e o processo através do qual o cuidar dos doentes e o tratar das doenças tornou-se objeto das práticas médicas. Baseado nas contribuições de Donnangelo \& Pereira e Gonçalves discute o processo que explica a apropriação das práticas médicas no modo de produção capitalista.

UNITERMOS: saúde e doença, práticas médicas, modo de produção capitalista

\section{INTRODUÇÃO}

\section{As doenças: a construção do conhecimento}

Tal como se diz correntemente: "Esculápio lhe prescreveu a equitação, os banhos frios, a marcha de pés descalços", dever-se-ia dizer: "A natureza do Todo lhe prescreveu uma doença, uma mutilação, a perda dos pais e outras provações semelhantes". Com efeito, prescreveu significa mais ou menos no primeiro caso: determinoulhe como mais conveniente à sua saúde, e, no segundo: 0 que se encontra na vida de cada um lhe foi de algum modo conveniente ao seu destino"...(MARCO AURÉLIO $^{10}, 1957$, p.68).

Analisar a evolução ou o desdobramento histórico dos modos de cuidar dos doentes significa colocar em evidência a questão da evolução da prática médica, como instituição que detém a legitimidade hegemônica do domínio desse cuidado e dos saberes relativos à doença e à saúde.

A compreensão e a elaboração dos modos de ver a saúde e a doença, - sentimentos, crenças e valores que configuram as representações que o homem tem de si mesmo e dos males que o acometem, bem como a estruturação dos saberes que mediatizam as formas de lidar com ambos - formas de proteger a saúde e prevenir e tratar as doenças, nas quais esses saberes se concretizam - ocorrem no mesmo processo em que vai se dando a organização dos modos de produção e a reprodução, biológica e social.

Nessa perspectiva, as explicações sobre doença e saúde são estruturadas no mesmo movimento em que se estruturam os saberes sobre a natureza, o homem e a relação entre ambos. Compreensão do processo enquanto histórico que incorpora, freqüentemente, uma idéia de determinismo, que se pretende entender no contexto do materialismo histórico.

A construção dos saberes e práticas médicas e a invenção dos meios de cuidar dos doentes - meios materiais e imateriais através dos quais as ações de cuidar se efetivam - ocorrem em um processo, durante o qual a medicina emerge como instituição encarregada de assistir os doentes e detentora legítima do domínio relativo à doença, como objeto de conhecimento e de intervenção. Esse processo inclui a invenção do hospital e da clínica, assim como, a constituição e a posterior substituição das práticas médicas excludentes** por outras formas de assistência. Os elementos mais significativos da institucionalização da medicina foram, sem dúvida, a organização discursiva e sistemática dos saberes e práticas médicas, a delimitação de seu objeto de trabalho e a apropriação e legitimação do domínio*** sobre esse objeto e sobre o espaço onde ele se insere.

É esse o entendimento de QUEVEDO ${ }^{13}(1989$, p.2), quando afirma que: "[...] conceptualizaciones que el hombre elabora sobre la realidad son el resultado de un

\footnotetext{
* Doutora em Saúde Coletiva. UNICAMP. Professora Universidade do Rio de Janeiro

** Entende-se por práticas médicas excludentes as formas de asilamento e reclusão compulsória que atingiram durante séculos os leprosos, tuberculosos e loucos. Essas práticas estão hoje sendo substituídas pelos tratamentos ambulatoriais e domiciliares *** O termo domínio foi utilizado no sentido de "âmbito de uma arte ou ciência, sentido que lhe é atribuído por FERREIRA, A.B.de H. Pequeno Dicionário da Lingua Portuguesa. Rio de Janeiro, Nova Fronteira, s/d
} 
proceso de produción, que hay que compreender como haciendo parte del proceso de produción general y que, por lo tanto, están demarcadas en el contexto de reprodución socio-cultural de las cuales son produtos".

A ruptura com a estrutura conceitual e metodológica da antigüidade clássica de explicação da doença e do adoecer, somente vai ocorrer, no espaço do saber médico, no século XVII, com T. Sydenham (QUEVEDO $^{13}$, 1989, p. 1).

As doenças, segundo FOUCAULT ${ }^{6}$ (1977, p.167), de Sydenham a Pinel, originavam-se e configuravam-se em uma estrutura geral de racionalidade em que se tratava da natureza e da ordem das coisas. Do início do Renascimento até o final do século XVIII, “o saber da verdade fazia parte do círculo da vida, que se volta sobre si mesma e se observa"; a partir de Bichat, ele é deslocado com relação à vida, e dela é "separado pelo intransponível limite da morte, no espelho da qual ela a contempla".

A idéia do equilíbrio interno, como uma expressão do equilíbrio externo, idéia sobre a qual se baseava a concepção de doença da antigüidade clássica - e da medicina hipocrática - prevaleceu no modelo conceitual que explicava a doença durante a Antigüidade e a Idade Média, esgotando-se, paulatinamente, no mesmo processo em que se deterioram as formas de organização social que caracterizaram aquele período. Segundo QUEVEDO $^{13}$ (1989, p. 1 e p. 6), Sydenhan, diante da incapacidade da medicina galênica para dar conta das grandes pestes que assolaram a Europa ao final da Idade Média, apoiando-se nas obras dos empiristas, especialmente Bacon e Locke, inicia um novo modo de conceber a doença, através de dois elementos importantes: o empirismo clínico, que se apoia na observação e uma nova classificação das doenças, - agudas e crônicas, ainda hoje utilizada. Visto desse modo, o que se dá nos séculos XVII e XVIII é a emergência de um novo olhar que observa e analisa, como princípio metodológico da estruturação dos saberes.

A observação, que o empirismo resgata, sistematizada agora pela interpretação do sinal físico, prolonga e especializa os sentidos e continuará sendo o ponto de partida do conhecimento da doença, tendo a razão como segundo passo. Razão que experimenta e intervém, ampliando as possibilidades do conhecimento.

A observação, descrição e classificação delimitam o paradigma da ciência moderna, e as idéias da experiência e da intervenção incorporam-se ao pensamento moderno. LUZ $^{9}$ (1988) e QUEVEDO ${ }^{13}$ (1989) concordam que o movimento típico do conhecimento científico moderno é prático, transformador da realidade. A experiência e a razão se fundem para permitir ao homem transformar e dominar o mundo.

A concepção anátomo-clínica é fruto da observação: a doença é identificada e localizada no órgão lesado ou doente. $\mathrm{O}$ estabelecimento da relação entre lesões anatômicas e sintomatologia clínica, estruturada com os subsídios da observação sistemática - quando razão e experiência tornam-se aliadas - desenvolve-se em um novo saber patológico. Saber que irá utilizar a anatomia como ponto de referência para a classificação das doenças e delimitar o espaço da doença, localizado no corpo.

Esta atitude metodológica, que se consolida como um grande avanço, identifica a doença em uma realidade visível, palpável e mensurável: a lesão. Lesão orgânica, evidência empírica da doença, cuja importância se estabelece com o desenvolvimento da anatomia patológica.

"A confiança na observação, como método de conhecimento da estrutura e de suas alterações, será a base de toda a medicina organicista, que se insere na mentalidade anatomopatológica" (QUEVEDO ${ }^{13}, 1989$, p. 11).

A trajetória histórica da razão científica moderna, assim como sua origem e bases sociais, são reconhecidas por $\operatorname{LUZ}^{9}$ (1988, p. 86), que entende que o deslocamento epistemológico da medicina - de uma arte de curar indivíduos (uma prática), para uma disciplina das doenças, (quando o saber que a prática contém é organizado e sistematizado) - supõe uma passagem histórica que se inicia no Renascimento, do final do século XV ao início do século XVI. "Até o século XVIII", diz a autora, "a temática prevalente da medicina será, cada vez mais, as entidades mórbidas, construídas como um sistema classificatório das morbidades, sistema elaborado com base na observação das doenças - sistemática, ordenatória, empírica - e em um modo particular de pensar as doenças, classificando-as por analogias e metáforas de similaridade com as disciplinas da botânica e da história". E, no leito do doente ou no microscópio do século XVII, serão procuradas as evidências que apontam para esta ou aquela doença. "Obtém-se, desta forma", acrescenta a autora, "uma dupla objetivação: a do corpo humano, que se torna sede das doenças e das doenças que se tornam entidades patológicas".

O paradigma clínico - concepção biológica da doença nos limites do organismo humano - versão dominante para a explicação da doença, instala-se então. E, nesse modelo, a concepção da doença é materialmente objetivada (LUZ ${ }^{9}, 1988$, p. 58 e segs.).

Do século XVII ao século XIX a filosofia social e a medicina ocidental incorporam um conjunto de novas categorias e conceitos que vão adquirir força de norma. Vários aspectos da vida social serão regulados e normatizados pela medicina, cujo poder se estabelece na constituição de sujeitos individuais, objetos de sua prática, e nas instituições e práticas sociais que tais conceitos, 
"expressos em enunciados científicos, dão forma e materialidade ao longo de todo o período" $\left(\mathrm{LUZ}^{9}, 1988\right.$, p.7).

A ciência que se engendra dentro da racionalidade moderna tem sua síntese epistemológica mediatizada a linguagem da razão, no método científico.

A clínica vai incorporar novas formas de aquisição do saber e novas regras de formação da percepção. Novos objetos vão se dar ao saber médico, na medida e ao mesmo tempo em que o sujeito cognoscente se reorganiza, modifica-se, passa a funcionar de uma nova forma (FOUCAULT $^{6}, 1977$, p. 53-57 e 101).

E ali, onde a clínica se configura, a experiência e o olhar se integram, um novo saber se constrói e toda a codificação dos objetos em que intervém se reformula. Mas a estrutura dessa nova definição da clínica é mais sutil e complexa: ela estava vinculada a uma reorganização do domínio hospitalar. "É preciso encontrar, para a manutenção dos hospitais, como, também, para os privilégios da medicina, uma estrutura compatível com os princípios do liberalismo e a necessidade de proteção social, entendida, de modo ambíguo, como a proteção da riqueza pela pobreza e a proteção dos ricos contra os pobres" (FOUCAULT 6 , 1977, p. 93).

Com o nascimento da clínica, a realidade positiva, visível, a espécie patológica, "deixa de ser uma realidade clínica com uma lesão aderida para converter-se em uma realidade anatômica" (Entralgo, apud QUEVEDO ${ }^{13}$, 1989, p.9).

As rupturas teóricas dos diferentes modos de perceber a doença, que assinalam formas diferenciadas de conceituar a enfermidade e o "locus" institucional de abordá-las, em termos de saber e prática clinicas entronizados no hospital, configurado como o espaço de eleição para o tratamento dos doentes - não obscurecem a continuidade da medicina moderna na construção de uma crença das doenças, tomando como campo laboratorial o corpo do doente.

Na primeira metade do século XIX, o positivismo de Comte estabelece um novo marco para o método científico: a imaginação se subordina à observação e à objetividade; e a construção do conhecimento é submetida ao princípio da neutralidade do sujeito. Todos os fenômenos são sujeitos a leis naturais invariáveis, cujo descobrimento preciso constitui a finalidade da ciência. Não há, nesse pressuposto, uma preocupação explícita com as causas geradoras dos fenômenos observados e identificados, mas as circunstâncias em que foram produzidos e as relações de sucessão e semelhança decorrentes são examinadas (COMTE ${ }^{3}$, 1978, p. 4-39).

Engendra-se, então, um novo paradigma da ciência, e, no âmbito dele, uma nova concepção de doença e saúde. É um processo que ocorre, dentro dos marcos da construção da ciência moderna, do empirismo que, reafirmando a importância da impressão sensorial, resgata a objetividade e a exterioridade da natureza, da observação, como prática sistemática de descoberta e de invenção que mediatiza o conhecimento, ao racionalismo que supõe ambos subordinados à razão. A versão organicista permeará a idéia de uma doença que se inicia antes dos sintomas e da lesão anatomopatologia, isto é de uma alteração funcional. A saúde se expressará pela ausência de sintomas e dos signos perceptíveis de uma patologia. A "cura" será substituída pela cessação de sintomas. E a idéia da cura como da eliminação da doença no corpo dos indivíduos incorpora-se à medicina moderna. Eliminação que se dará pela intervenção da medicina no corpo dos indivíduos, intervenção que se estende ao "corpo social", sobre as condutas e sobre as práticas sociais.

A mudança mais significativa vem a ser o fato de que, sem abandonar o paradigma clínico baseado na observação dos sintomas, do mesmo modo que muitas concepções hipocráticas não haviam sido abandonadas, a medicina irá incorporar, via a filosofia positivista e a adoção do conceito de função, a fisiopatologia, a partir da qual será desenvolvida a concepção de saúde como um processo.

A síntese do modelo explicativo mecanicista, "o corpo humano, morfologicamente visto como um grande engenho", do método experimentalista e da linguagem matematizante converte-se em um dos fundamentos da racionalidade moderna $\left(\mathrm{LUZ}^{9}, 1988, \mathrm{p} .84\right)$. E, estendendose aos fenômenos sociais - a racionalização do social envolve, também, segundo a autora, a "criação de instituições" e a organização de políticas e práticas sociais, que têm por característica a objetivação dos corpos humanos. Políticas e práticas que ficam evidentes com a criação de técnicas e de instituições de controle - asilos psiquiátricos, prisões, escolas, hospitais - em que os sujeitos da racionalização moral são sujeitos construídos. E os sujeitos que povoam essas instituições são os que habitam as cidades recém povoadas - soldados, prostitutas, loucos, aleijados de guerra e da paz, mendigos e doentes de doenças infames como a sífilis, a lepra, a varíola, que devem ser tratados moral e fisicamente.

TELLES et al. ${ }^{16}$ (1993), discutem a doença em uma abordagem antropológica, e, ultrapassando o sentido da própria expressão lingüística da racionalidade científica, utiliza em sua reflexão as categorias de espaço e tempo. Emergem de sua análise conotações novas, de um saber filosófico antes que histórico, que materializa o fenômeno, tornando-o visível e observável. Visibilidade que se encontra com a retomada do princípio da etiologia natural das doenças, dentro dos marcos do empirismo, e abre o caminho para o desenvolvimento da medicina científica moderna.

Assim, enquanto os paradigmas são substituídos, 
as formas de intervenção vão sendo elaboradas e a organização das práticas adquire consistência. Aos modos de compreender a saúde e a doença sucedem-se os diferentes modos de lidar com ambos: a elaboração de práticas e saberes, consubstanciados em um trabalho, de que o corpo dos indivíduos consiste no primeiro objeto, e a criação e organização de formas institucionalizadas de intervenção coletiva concretiza sua articulação social.

E a medicina consolida-se enquanto instituição de tratamentos dos doentes e, ao mesmo tempo, enquanto instituição de poder em relação às questões de saúde e doença e às relações sociais delas derivadas.

\section{DOENÇAS E DOENTES: A APREENSÃO DAS PRÁTICAS MÉDICAS NO MODO DE PRODUÇÃO CAPITALISTA}

$\operatorname{ALVES}^{2}$ (1993), que utiliza, assim como TELLES et al. ${ }^{16}$ (1993), concepções buscadas na antropologia, inicia seu artigo A Experiência da Enfermidade: Considerações Teóricas afirmando que "as crenças e os valores constituem respostas socialmente organizadas para a doença. Refletem o complexo interativo entre grupos sociais, instituições, padrões de relacionamento e um corpo específico de conhecimentos" (ALVES ${ }^{2}, 1993$, p.269). O autor utiliza como categoria analítica a "experiência da enfermidade", isto é, a experiência vivenciada pelo sujeito da enfermidade, como objeto privilegiado de seu interesse, afirmando pretender compreender as dimensões cognitivas e sociais incorporadas nas representações individuais. Segundo o autor o caráter intersubjetivo da enfermidade implica na existência de certos parâmetros ou quadros de referência graças aos quais é construído o significado experiência médica. O texto, que contém elementos analíticos que ultrapassam os objetivos deste trabalho, não se adianta em direção ao questionamento das práticas médicas e suas articulações.

É, ainda, no quadro da antropologia médica, que SEVALHO $^{14}$ (1993) desenvolve seu artigo sobre as representações sociais de saúde e doença, numa abordagem histórica que insere o tema na concepção histórica atual e na categoria tempo. O autor descreve as diferentes concepções de doença que se sucederam ao longo da história, do sobrenatural ao natural e deste ao social, adiantando-se em direção ao domínio do ambiente social pelo conhecimento médico e à emergência da medicina social, a partir dos movimentos revolucionários dos meados do século XIX, que, no entanto, não consegue assistir as pessoas doentes com seus pressupostos. Os doentes continuaram a necessitar de assistência.

Numa abordagem que busca o suporte da sociologia para analisar a doença e a medicina, ADAM
\& HERZLICH ${ }^{1}$ (1994) pretendem estudar as grandes linhas da transformação do "estatuto dos doentes" e os tipos de relações sociais que se instauram em torno das doenças e de seus determinantes sociais. Os autores analisam a evolução da medicina de Hipócrates ao desenvolvimento da medicina científica ocidental e ao nascimento da clínica. A profissão médica e o conceito de profissão são objetos de uma reflexão especial de ADAM \& HERZLICH ${ }^{1}$ que colocam em discussão a ascensão da medicina como instituição hegemônica no cuidado e assistência dos doentes e analisam o conceito de profissão, entendendo que os profissionais se distinguem pelo nível de formação abstrata e especializada, "uma orientação de serviço", (que se traduziria por um compromisso) e, autonomia no exercício de sua profissão, pelo qual respondem a seus pares e destacam a relação da importância da profissão médica ao valor atribuído à saúde.

Algumas questões assinaladas por ADAM e HERZLICH $^{1}$ (1994) constituem indicadores da perspectiva adotada pelos mesmos ao discutir esse tema. É o caso da dupla evolução da medicina e da proteção social, que, ao colocar em evidência a doença e a condição de doente, atribui à profissão médica uma tarefa normativa e ao saber médico um valor prescritivo e, conseqüentemente, um poder. Poder que se revela na afirmação dos autores de que a saúde é hoje um dos principais setores dos países desenvolvidos.

O texto de ADAM \& HERZLICH ${ }^{1}$ (1994), que se apoia em parâmetros sociológicos atuais e coloca em evidência temas que estão sendo objetos de reflexão hoje, aproxima-se, com freqüência, das categorias analíticas da Antropologia Social, especificamente das representações sociais, informações e crenças, como suporte das ações dos sujeitos da doença e, dessa maneira, atribui uma importância especial aos aspectos subjetivos que estas expressam. Ao tratar da relação médico-doente e discutir o lugar da medicina na sociedade moderna, os autores chegam ao Hospital como o lugar da produção do trabalho médico, de onde pode-se retomar a perspectiva deste trabalho, que está voltado, especialmente, para a articulação das práticas médicas aos modos de produção capitalista.

Para atender esta perspectiva retoma-se as contribuições de DONNANGELO \& PEREIRA ${ }^{4}$ (1976) e GONÇALVES ${ }^{7}$ (1984), cujos obras são voltados para a relação entre a medicina e o capitalismo. Esses autores entendem a necessidade de abrir espaços de discussão dentro das relações entre a prática médica e a história, bem como a compreensão das funções dessa prática em suas relações com as dimensões constitutivas de cada tipo macro-histórico de organização social. A análise de DONNANGELO \& PEREIRA ${ }^{4}$, sobre a relação da 
prática médica com as demais praticas sociais, estendese aos meios de trabalho empregados pela medicina que, segundo a autora, tendem a ser compreendidos como um "conjunto de recursos tecnológicos mais ou menos complexos cuja historicidade se perde tanto no seu caráter científico, como no obscurecimento de tal caráter científico" e na instauração de uma relação particular entre o médico e o objeto de sua prática. Como entendem os autores, "a articulação da medicina com as demais praticas sociais constitui, o ponto estratégico de que melhor se pode apreender o seu caráter histórico" (DONNANGELO \& PEREIRA ${ }^{4}, 1976$, p. 26 e p.15).

DONNANGELO \& PEREIRA ${ }^{4}$ (1976), ao analisarem a evolução histórica da prática médica, levam em conta, um duplo sentido: "Historicidade dos meios e a historicidade dos objetivos", objetivos que segundo ela "se encontram dados fora dela (da medicina), na estrutura econômica e político-ideológica das sociedades nas quais se integra". E sintetiza o caráter dessa história cronológica em termos de "aprendizagem progressiva por parte da humanidade dos meios idôneos para curar a enfermeidade" (DONNANGELO \& PEREIRA ${ }^{4}, 1976$, p. 16, 22 e 25). Em outras palavras, entende-se que, no sentido referido pelos autores, os modos de conhecer as doenças e de lidar com elas- saberes e práticas que constituem a prática médica, assim como os aparatos tecnológicos que viablizam as práticas- conquanto conformados pela história incorporam em seus objetivos, valores que transcendem a história. "Os meios de produção", [e os serviços de saúde constituem meios de produção de serviços], "não se sucedem meramente", afirmam DONNANGELO \& PEREIRA ${ }^{4}$ (1976, p.18), "correspondem e fundamentam modalidades de articulação entre o trabalho, seu objeto, seus produtos e a forma de seu consumo". Foi esse o pressuposto que fundamentou o desenvolvimento da clínica, como meio de trabalho, cuja emergência coincide com uma nova articulação entre a medicina e a sociedade, o que só se dá pela modificação de todo o campo da prática e da "função social do médico". "Garantindo sua competência, atribuindo-lhe a tarefa de limitar as epidemias, controlar o contágio, preservar regiões inteiras, a burguesia the atribui um território e um modo de exercícios novos" (DONNANGELO \& PEREIRA ${ }^{4}, 1976$, p. 19).

A incorporação da medicina ao modo de produção capitalista, consolida-se, segundo DONNANGELO \& PEREIRA ${ }^{4}$, à medida que a produção de serviços médicos torna-se cada vez mais apropriada à produção de mais valia. "A prática médica articula-se à produção de mais valia, em particular da mais valia relativa, através do aumento de produtividade do trabalho". (DONNANGELO \& PEREIRA ${ }^{4}, 1976$, p.35). Essa é a ótica encontrada em Pollack, citado pela autora (p. 35 e 36 ) que entende que, “...dirigindo-se à força de trabalho, o ato terapêutico eleva seu nível ou contribui para sua manutenção no quadro de uma reprodução [...] a medicina visa a definição permanente de um nível de produtividade[...]. E esse é, também, o sentido encontrado por FOUCAULT, para quem convergência espontânea e profundamente arraigada entre as exigências da ideologia, da política e as da tecnologia médica [...]. Com um só movimento, médicos e homens de Estado reclamam, em vocabulário diferente, porém por razões essencialmente idênticas, a supressão de tudo o que possa ser obstáculo para constituição deste novo espaço: os hospitais,[...]" (FOUCAULT ${ }^{5}, 1966$, p. 63 e 64).

Tomando por referência as categorias de trabalho e classe social, no sentido que a ambas é atribuído pelo marxismo, e, entendendo ser a classe social, em última instância, o objeto do trabalho médico, GONÇALVES ${ }^{7}$ (1984), analisa a prática médica enquanto prática social, no modo de produção capitalista. Para o autor a medicina aparece "como prática reiterada das sociedades humanas, como ato humano, como atividade de uma parte dos membros de uma sociedade [...]. A medicina aparece pois, em primeiro lugar como trabalho" (GONÇALVES ${ }^{7}$,1984, p.21). E a categoria trabalho como atividade institucionalizada, validada, fixada e regulada normativamente, ou seja, integrada a um sistema social, atua como fonte de obtenção, por quem a desempenha, dos meios naturais de existência produzidos e indispensáveis para a satisfação das necessidades que são historicamente conformadas e produzidas (L. PEREIRA, apud GONÇALVES ${ }^{7}$ 1984, p. 22).

Qualquer que seja o sentido que lhe é atribuído, ao cuidado e assistência aos doentes é inerente uma idéia de doença e de saúde e um pressuposto de carência e de necessidade nas quais se conforma o objeto da prática médica. No entanto, essa carência, atributo do indivíduo ou coletivo de indivíduos, não é de quem define e determina a prática que a satisfaz. É a medicina que a identifica, define e, através de seus agentes e aparatos institucionais, determina a prática adequada para sua satisfação. Desse modo, o objeto da prática e a necessidade que a inspira não se distinguem: o objeto da prática é a própria necessidade. "A medicina não se propõe na prática lidar com outra coisa do que as próprias necessidades que levam o doente a ela" (GONÇALVES ${ }^{7}$ 1984, p. 36). De fato tanto a categoria prática médica, desenvolvida por DONNANGELO \& PEREIRA ${ }^{4}$ (1976), como a de trabalho médico e sua relação com a classe social, formulada por GONÇALVES ${ }^{7}$ (1984), apontam ambas para o mesmo sentido: a idéia que, partindo do pressuposto de uma historicidade do conjunto da sociedade, as práticas e o trabalho médico estão contidos nessa historicidade e apreendidos em sus movimento de mudança. 
Prática articulada às demais práticas sociais, trabalho ou serviço que atende a necessidades e carências previamente definidas, porque há "homens que se sentem doentes", os saberes que constituem a prática médica dizem respeito aos homens, às suas doenças e aos modos de lidar com elas.

Os modos através dos quais as práticas médicas se estruturam, suas formas de organização, suas instituições, refletem não só os significados que, em cada época, o homem atribui a si mesmo e à sua doença, como, também, os mecanismos que viabilizam a articulação dessas práticas ao sistema de produção e reprodução social.

A história das instituições médicas, sejam incorporadas no ideário das pessoas e coletividades, ou consolidadas em condutas e práticas, está permeada por determinações econômicas e políticas. O significado de suas articulações com as demais práticas sociais tornase evidente nos objetivos que lhe são atribuídos. É nesse sentido que a medicina se vincula ao Estado, instância do domínio político que promove a mobilização dos recursos ideológicos capazes de aglutinar provisoriamente classes e camadas sociais (DONNAGELO \& PEREIRA ${ }^{4}, 1976$ ).

A incorporação das práticas médicas e de suas instituições ao modo de produção capitalista coloca em evidência o corpo, objeto do saber e da prática médica,corpo dos indivíduos e dos coletivos de indivíduos. Esse corpo que também é, no modo de produção capitalista, mais que tudo, agente de trabalho. Nesse entendimento, o objeto de trabalho médico se constitui na força de trabalho que esse corpo representa, cuja necessidade basicamente econômica de reprodução permeia em todos os momentos a organização do trabalho médico. E esse corpo, objeto de uma prática e agente de um trabalho, portador de uma força de trabalho, adquire os significados particulares que lhe são atribuídos em cada estrutura de produção social, significados que se definem no domínio do político, do cultural e do econômico. GONÇALVES ${ }^{7}$ (1984), ressalva que a utilização de um referencial histórico para situar a prática social, não eqüivale a limitar o significado das determinações sociais e estruturais ao dos condicionamentos que se lhe anexaram. Tampouco significa compreender o processo como uma prática delimitada, transfigurada, "por sua existência contingente no âmbito de situações concretas históricas inevitáveis" (GONÇALVES ${ }^{7}, 1984$, p. 11).

Situar a prática social por sua historicidade, não equivale, portanto, reduzi-la, exclusiva e restritamente aos elementos significativos que podem ser deduzidos daquelas determinações. O movimento dialético em que os saberes científicos se desenvolvem, saberes sobre o corpo humano normal e doente, atende à necessidade "formulada pela existência de uma prática que procurava dar conta das situações, historicamente variáveis, designadas como "modo de viver a vida", socialmente desacreditados". Essa é a interpretação de GONÇALVES ${ }^{7}$ (1984,p.63-64), que reconhece a subordinação da ciência à prática de cada momento histórico e à uma forma de organização social que corresponde a um momento histórico em sua própria estruturação. "Em outros termos, a estrutura do conhecimento, os objetos que ela deve conhecer, os métodos e técnicas de investigação, se conjugam em forma histórica mais ou menos individualizáveis e que correspondem a outras tantas formas históricas assumidas pela prática".

Nessa perspectiva identifica-se, segundo o autor, duas linhas de interpretação, a primeira das quais privilegia a essência supra histórica da prática médica, sua determinação imperiosa das condições sociais que atuam sobre a mesma. Essa interpretação, se entendermos as atitudes sobre o corpo e a valorização da saúde e da doença como parte das condições sociais, pode ser encontrada em (SIGERIST ${ }^{15}$ 1974, p. 19) que, de outra perspectiva, afirma que ..."'Os traços característicos da profissão médica em cada época estão determinados, em um amplo grau pela atitude da sociedade ante o corpo humano e sua valorização da saúde e da doença. $\mathrm{O}$ propósito da medicina foi sempre o mesmo: curar a doença e, eventualmente, preveni-la. A medicina sempre significou serviço e, portanto, em todos os tempos, se requererem dos médicos certas qualidades: pronta disposição para ajudar, conhecimento sobre a natureza da doença e destreza para curá-la".

A segunda linha de interpretação, indica uma posição metodológica em que se observa uma diversificação dos enfoques, desde os dominantes na sociologia americana até os inspirados no materialismo histórico. Nesse enfoque as funções do setor saúde são determinadas pelas mesmas forças econômicas que determinam as estruturas das classes sociais. É a interpretação de NAVARRO para quem o sistema de serviços de saúde está determinado primariamente, "ainda que não exclusivamente, pelas mesmas forças que determinam o conjunto da formação social". [...] Considero a medicina como o resultado dialético das forças que existem tanto fora como dentro dela mesma" (NAVARRO $^{11}, 1979$, p. 19-20). Esta concepção é reafirmada pelo autor em outro texto (NAVARRO ${ }^{12}, 1986$, p. 31 e segs.).

Partindo de um novo enfoque, HERZLICH \& PIERRET $^{8}$ (1984, p. 212), introduzem na análise dos serviços de saúde a noção do valor do capital biológico, representado pelo corpo, capaz de produzir e reproduzir valores e capital, conceito que retorna a DONNANGELO \& PEREIRA ${ }^{4}$ (1976), em sua referência à força de trabalho como objeto da medicina, através da qual se articula com a produção econômica. E com essa noção 
de valor articula-se um novo protocolo da relação entre a sociedade e o indivíduo doente, um novo pacto. A doença é socializada, torna-se atribuição do Estado e, por conseguinte da sociedade, e essa socialização da doença, ou de seus custos, delimita o aparecimento e o reconhecimento de um personagem, o doente, face ao qual a sociedade tem deveres e obrigações. E através das suas relações com a ordem social, a doença, que daqui em diante é pensada como tal, transcende o indivíduo para se tornar um fato social. A assistência pública, posta em funcionamento pelas autoridades políticas, teria a finalidade de remediar a insegurança que representariam, para o conjunto social, certas categorias de excluídos, assim como, a proteção desse valor que recém fora atribuído ao indivíduo. Desse modo explica-se que ela (a assistência pública) "tenha se revestido, em sua origem, de um significado mais político que social, por se encontrar ligada a defesa e a consolidação das coletividades políticas em vias de formação" (HERZLICH \& PIERRET $^{8}, 1984$, p. 213.). Com efeito, os grupos particulares, tais como comunidades religiosas, as confrarias e associações de operários, assumiram o encargo de beneficência e de socorro, enquanto o poder público se afirmava progressivamente na manutenção da ordem e consagração dos valores comuns da sociedade global.

O Estado Moderno formula, além de uma nova ciência, um novo conceito da relação do Estado com o cidadão, categoria recém estatuída. Na Declaração dos direitos do Homens de 24 de junho de 1793, está afirmado o dever da sociedade em relação aos cidadãos desgraçados, desafortunados, através da ligação subsistência - trabalho- socorro. "Os socorros públicos são uma dívida sagrada. A sociedade deve a subsistência dos cidadãos desafortunados, seja em sua procura de trabalho, seja assegurando os meios de existir àqueles que estão fora das condições de trabalhar" (G. Perin apud HERZLICH \& PIERRET $^{8}, 1984$ p. 212). Verificase, assim, que o reconhecimento da obrigação do Estado de cuidar da saúde dos cidadãos é postulado há pelo menos dois séculos.

HERZLICH \& PIERRET $^{8}$ (1984), entendem que a ligação do direito de trabalho e direito à assistência, que aparece no ideário do século XVIII, expressa uma idéia de organização social em que está contida uma nova concepção de relação entre a sociedade e seus membros.

A doença, assimilada à incapacidade de trabalho, reconhecida pela medicina - os médicos participam da socialização da doença, conferem-lhe identidade e a denominam - é transformada e se inscreve nos novos laços que definem a ordem social. Ser doente torna-se um direito: o direito de parar de trabalhar e de receber cuidados. E o doente aparece como um novo personagem na cena social. Os progressos da patologia contribuem para a emergência de uma figura individualizada do doente, a quem, será reconhecido um estatuto de indivíduo inativo, - liberado dos deveres da produção e aceito como tal. Os novos deveres e direitos e um modo original de se relacionar com o conjunto social vão se definir. Mas esse doente a quem se reconhece, também, o direito ao tratamento de sua doença, não é garantido o acesso aos serviços de saúde. Por força de sua apreensão no modo capitalista de produção as práticas médicas são entronizadas no mercado e os serviços de saúde tornaramse mercadoria.

\section{THE DISEASES AND THE SICK - THE UNDERSTANDING OF MEDICAL PRACTICES IN CAPITALISM}

This article discusses the diseases and the sick as well as how the process from which to take care of them became object of medical practices. Based on Donnagelo and Gonçalves contributions, the author discusses the process that explains medical practices appropriation by the capitalism.

KEY WORDS: health and diseases, medical practices, capitalism

\section{LAS ENFERMEDADES Y LOS ENFERMOS - LA APREHENSIÓN DE LAS PRÁCTICAS MÉDICAS EN EL MODO DE PRODUCCIÓN CAPITALISTA}

Este artículo discute las enfermedades y los enfermos y el processo hacia el cual el cuidar de los enfermos y el tratar las enfermedades se convirtieron en objeto de las prácticas médicas. Basado en las contribuiciones de Donnagelo e Gonçalves discute el proceso que explica la apropriación de las prácticas médicas en el modo de producción capitalista.

TÉRMINOS CLAVES: salud y enfermedad, prácticas médicas, modo de produción capitalista 
REFERÊNCIAS BIBLIOGRÁFICAS

01. ADAM P.; HERZLICH, C. Sociologie de la maladie et de la médicine. Paris, Natham Université, 1994.

02. ALVES, P.C. A experiência da enfermidade: considerações teóricas. Cadernos de Saúde Pública, 9(3): 263-271, 1993.

03. COMTE, A. Curso de filosofia positiva. São Paulo: Abril Cultural, 1978.(Os pensadores).

04. DONNANGELO, M.C.F.; PEREIRA, L. Saúde e Sociedade. São Paulo: Duas Cidades, 1976. $124 p$.

05. FOUCAULT, M. El nascimiento de la Clínica. Mexico: Siglo XXI, 1966.

06. FOUCAULT, M. O nascimento da Clínica. Rio de Janeiro: Forense-Universitária, 1977.

07. GONÇALVES, R.B.M. Medicina y História: raices sociales del trabajo medico. Mejico: Siglo Veintiuno, 1984. 204 p.

08. HERZLICH, C.; PIERRET, J. Malades d'hier, malades d'aujourd'hui. Paris:Payot, 1984.
09. LUZ, M.T. Natural, Racional, Social. São Paulo: Editora Campus, 1988.

10. MARCO AURÉLIO. Meditações. Rio de Janeiro: Livraria José Olímpio, 1957.

11. NAVARRO, V. La medicina bajo el capitalismo. Barcelona: editorial crítica, 1979

12.____ Classe social , poder político e o Estado e suas implicações na medicina. In: Texto de apoio de ciências sociais I. Rio de Janeiro: ABRASCO,1986.

13. QUEVEDO, E. EI Proceso Salud -Enfermedad: hacia una clínica y una epidemiologia no positivistas. Bogotá: Pontifica Universidad Javeriana, Faculdad de Estudios Interdisciplinares, 1989.

14. SEVALHO, G. Uma abordagem histórica das representações sociais de saúde e doença. Cadernos de Saúde Pública, v. 9, n. 3, p. 349-363, 1993.

15. SIGERIST, H. Historia y la sociologia de la medicina. Bogotá: Gustavo Molian Ed. 1974.

16. TELLES, F.S.P. et al. Doença e tempo. Cadernos de Saúde Pública, v. 9, n. 3, p. 309-315, 1993. 